\title{
Determination of Normalized Difference Vegetation Index (NDVI) by Applying Disco-Pro AG Drones in Vineyards
}

\author{
P.S. Efendyan, T.A. Hovhannisyan, T.M. Hakobyan \\ Armenian National Agrarian University \\ armgeoinform@mail.ru, tigranh20@mail.ru, tmhakobyan@gmail.com
}

\section{A R T I C L E I N F O}

Keywords:

drones,

digital model,

NDVI vegetation index, monitoring,

soils,

precision agriculture

\begin{abstract}
A B S T RA C T
Reliable and up-to-date data on every soil segment of the land areas cultivated for the contemporary land utilization is of vital significance.

Currently, the efficient planning and control over the agricultural activities is hardly possible without any reliable and updated information on the yield and agricultural soil types, whereas implementation of drones in the field of land management and in agriculture, on the whole, is one of the most perspective directions, since unlike the artificial sattelites, they provide more precise and guided images for the given location.

The aim of the research is to produce the digital field model and NDVI map for the crops by applying Parrot Disco-Pro AG drone kit.
\end{abstract}

\section{Introduction}

Land is the most vital natural resource for any country; it is also the material base of production sector, spatial background of economic allocation and development, as well as the main source for agricultural production. Soil is the natural base on which people live and work. In this regard, the efficient use of land resources is one of the most paramount issues faced by any country; thus, retrieving land information is very important to handle the mentioned problem. The availability of comprehensive soil data enables to make the land resource management system more effective. Particularly, in recent years, related to the global climate changes, the rational land utilization has become the main problem for many countries. In case of Armenia, the mentioned issue is getting more exacerbated due to the scarcity of land resources (Efendyan, 2017). There are multiple cases related to irrational use of agricultural lands, such as large-scale deforestation, increase of the urban and mining land areas at the expense of agricultural lands, etc. Therefore, detailed information on the land resources is viewed as a high priority. Receiving such type of qualitative and quantitative information is possible only by applying the latest equipment and technologies (GIS systems, satellite positioning systems, pilotless vehicles/ drones) in the agricultural sector; besides, the mentioned technologies can be used for solving multiple agricultural problems, including those related to precision agriculture (satellite farming), soil monitoring, yield forecasting and ecological control (Efendyan, 2010). 


\section{Materials and methods}

Parrot Disco-Pro AG drone (Figure 1) has been used for conducting monitoring in the vineyards of Van Ardi winery.

The Parrot Disco-Pro AG drone captures photo of about 80 ha land area during a single flight at $120 \mathrm{~m}$ altitude. The flight distance is $2 \mathrm{~km}$ and the average duration - 25-30 minutes. Parrot Sequoia multispectral sensor is installed on the mentioned drone, which is a system consisting of 5 cameras. One of them is a RGB camera and the other 4 are multispectral cameras, which capture the plant reflected light in 4 different specters: green, red and two infrared bands, which are invisible to the naked eye. The Sequoia has got its own GPS within the multispectral sensor, which considerably increases the survey accuracy (d'Oleiere Oltmanns, 2012).

The technical descriptors of light reflectance of Sequoia multispectral sensors are introduced in Table 1.

Sequoia is a powerful instrument for conducting research and introducing precision agriculture. After producing field maps based on the drone, satellite and laboratory data and by marking the descriptive data for every centimeter, the farmer gets an opportunity to allocate resources more efficiently.
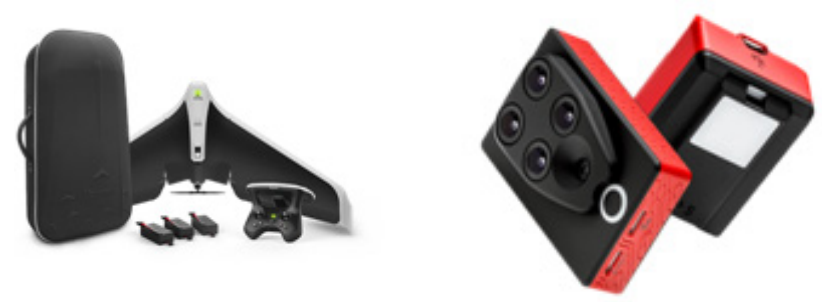

Figure 1. Parrot Disco-Pro AG drone and Parrot Sequoia multispectral sensor.

Table 1. Technical descriptors of four bands in Sequoia multispectral sensors*

\begin{tabular}{|l|c|}
\hline Band & $\begin{array}{c}\text { Reflectance Wavelength, } \\
\mathbf{n m}\end{array}$ \\
\hline Green & $530-570$ \\
\hline Red & $640-680$ \\
\hline Near infrared & $730-740$ \\
\hline Infrared & $770-810$ \\
\hline
\end{tabular}

*Composed by the authors.
As a result, it becomes possible to avoid the resource overrun in the areas, where they were previously overused and to increase the productivity of the field plots where irrigation, cultivation and fertilization activities were formerly incomplete.

This approach can increase the yield amount per unit land area reducing the expenses and raising the yield capacity per square meter up to the maximum. Besides, this technology enables to increase the yield quality and reduce the environmental load. The precision agriculture is also based on the application of the maps with accurate field descriptions. There are surely cadastral maps for each field, where the land plot borders are marked, anyhow, they hardly contain any useful information for the organization of agricultural activities.

Along with the land borders also some precise data on the soil chemical composition, its humidity level (including the depth of underground waters), the amount of emitted solar radiation, the slope steepness against the horizon, as well as on the prevailing winds, forests, ponds and industrial objects are required. The more factors are considered and the more detailed maps are drawn, the more efficiently computer, drone and satellite technologies can be used (Efendyan and Hovhannisyan, 2018).

The application of such technologies will enable to optimize the consumption rates of raw products and materials (fuel, seeds, fertilizer, water, etc.) in the agricultural croplands, to increase the yield capacity of the cultivated land areas, as well as yield quality.

Conducting surveys over the agricultural croplands through drones has become widespread throughout the world for the last 5-6 years. The study and investigation of the received data by applying spectral sensors is becoming a commonplace day by day, while in Armenia there is still lack of practice for their application. Thus, the objective of the current work is to develop and introduce the mentioned technologies and their application ways in the Republic of Armenia considering the world practice, which is not possible without relevant experiments and scientific analyses. To this end it was planned to produce the digital field model and NDVI map for crops by applying Parrot Disco-Pro AG kit.

NDVI normalized difference vegetation index is a common indicator of the photosynthetically active biomass (usually called Vegetation Index) (Hovhannisyan, 2017).

This index is calculated through the following formula:

$$
N D V I=\frac{N I R-R E D}{N I R+R E D},
$$


where $N I R$ is the reflection coefficient in the near-infrared band, $R E D$ is the reflection coefficient in the red spectrum/ band.

The ratio of plant light absorption and reflection in the red $(R E D)$ and near-infrared (NIR) color bands is considered.

This index is actively used in agriculture for the solution of general-purpose tasks. The more exuberant the flora during the vegetation period is, the higher the mentioned index is. Thus, the value of NDVI index can identify the development level of the green mass throughout the vegetation period. The index of NDVI is a relative value and doesn't address the absolute value of leaves and green mass; anyhow based on this indicator it would be possible to provide robust assessments on how well or bad the plant is developing. NDVI index is changing throughout the whole plant growing period and its value is different in the growing, flowering and maturation phases of the plant (Mozgovoy and Kravets, 2009).

\section{Results and discussions}

The experiments were conducted twice a month in June and July, 2018. The area was video captured at 100 meter altitude.

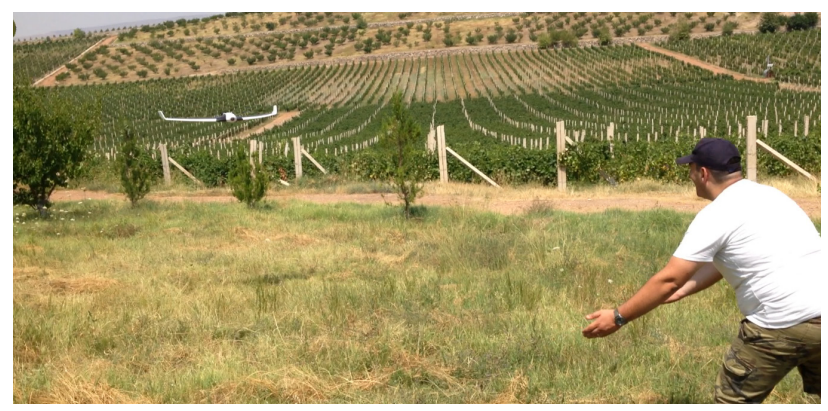

Figure 2. Landing of Parrot Disco-Pro AG drone.

NDVI vegetation index enables to identify the problem/ vulnerable land sites in quick and highly precise manners. With the map of vegetation index it would be possible to keep track of the vegetation process finding out whether it develops regularly or adversely through the identification of dried and diseased plants. When detecting the problem land segments it becomes possible to approach these sites with precise coordinates and to search out the disease cause. The reasons can be different starting from soil mechanical composition and its texture up to pests and diseases. Based on the retrieved data the field-related specialists take decisions and plan relevant measures.
After field activities, the data processing was implemented in the desk research through the corresponding software programs (Magnotta, 2015). In the result the digital field model was produced with $7 \mathrm{~cm} /$ px precision (Figure 3 ).

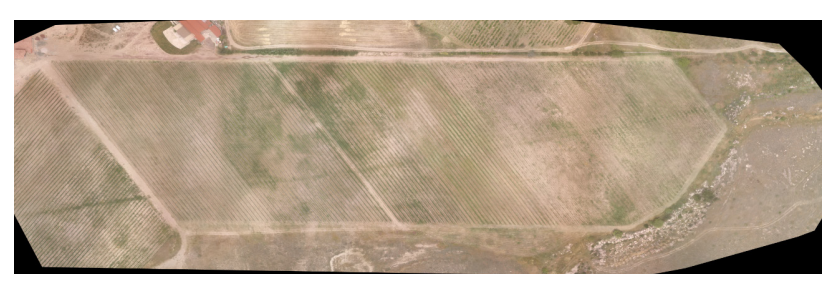

Figure 3. Digital field model.

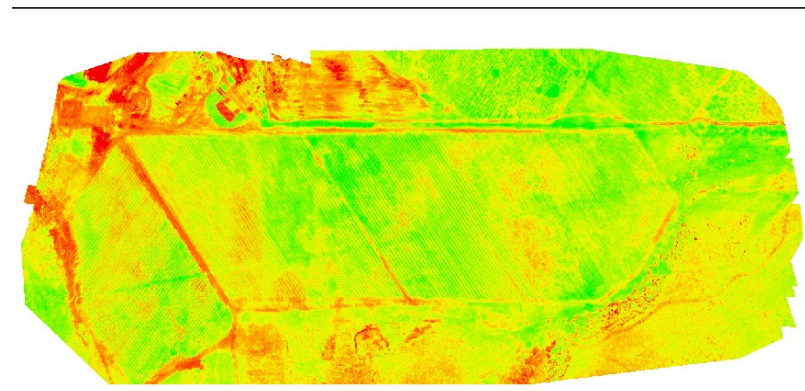

Figure 4. Digital NDVI model of the field for June.

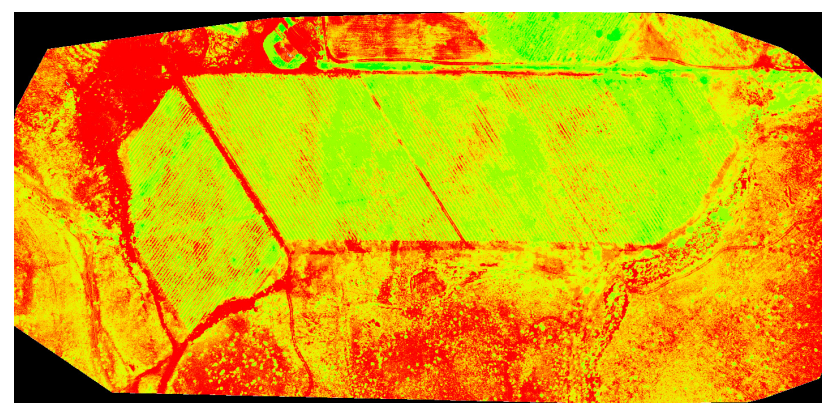

Figure 5. Digital NDVI model of the fields for July.

In the second stage NDVI digital model was produced (Figure 4, 5). Upon the color separation the field plots with dense vegetation and those where the vegetation growth has stopped or is completely missing, are clearly distinguished. The NDVI index of 0.85 has amounted to 0.9 within a month.

The vegetation maps composed through the spectral cameras enable to detect the pests or diseases at the early stage of their development, when the latter aren't visible with a naked eye and are not completely spread along the entire field, it is also possible to identify the focus of their 
occurrence, if they are developed and penetrated from the neighboring lands.

It is possible to implement zoning in the produced maps by demarking the land sites, which need to be studied more comprehensively. Then these data with accurate and precise coordinates can be sent to farmers or agronomists.

\section{Conclusion}

The contemporary technologies, such as pilotless aerial vehicles (drones) can be of significant importance for the increase of agricultural productivity.

Since no agricultural crop monitoring with the spectral sensors installed in these drones has been implemented in Armenia yet, the studies and analyses conducted by our research group are somehow the starting steps for the implementation of the mentioned tools in the precision agriculture.

Application of drones in land management sector and in agriculture on the whole, is one of the most perspective directions for the use of these technologies. They enable to get up-to-date and effective data when required; besides the cached information for different time periods provides a wide opportunity to implement analyses on various procedures (Hovhannisyan, et al., 2018).

Due to the NDVI digital map it is possible to view the problem areas, where the vegetation is disturbed, as a result of which we can find quick and local solutions to the problems fixed in the mentioned areas.

So, the prospects of using drones in agriculture are diverse and they are continuously recording progress along with science development. Drone surveying is a new and developing technology in the agricultural sector, which can play a specific role in the development of the agriculture in Armenia.

\section{References}

1. Efendyan, P.S., Hovhannisyan, T.A. (2018). The Possibilities of Using Joint Data Received from the Sattelite Imagees and Pilotless Aerial Vehicles in Agriculture. The Modern Achievements in Geodesic Science and Production. - Lviv, - Issue 1(35), - pp. 56-58.

2. Efendyan, P.S (2017). Some Issues on the Efficient Management of Land Resources, Agriscience, N 1-2, - pp. 26-32.

3. Efendyan, P.S. (2010). The Issues of Land Resource Management and their Solution Ways in the RA. Agriscience, - N 7-8, - pp. 308-312.

4. d'Oleire Oltmanns, S., Marzolff, I., Daniel, Peter, K., Ries, J.B. (2012). Unmanned Aerial Vehicle (UAV) for Monitoring Soil Erosion in Morocco // Remote Sens. - N 4(11), - pp. 3390-3416; doi:10.3390/rs4113390.

5. Hovhannisyan, T., Efendyan, P., Vardanyan, M. (2018). Creation of a Digital Model of Fields with Application of DJI Phantom 3 Drone and the Opportunities of its Utilization in Agriculture // Annals of Agrarian Science - Vol. 16, - issue 2, - pp. 177-180.

6. Hovhannisyan, T.A. (2017). Determination of the NDVI Vegetation Index by Remote Sensing of the Earth (Based on the Example of Arzakan Community of Kotayk Region) // Bulletin of National Agrarian University of Armenia. Yerevan, - N 4, - pp. 88-92.

7. Magnotta, J. (2015). Use of Drones in GIS, https:// www.gislounge.com/use-drones-gis/ (accessed on 03.04.2021).

8. Mozgovoy, D.K., Kravets, O.V. (2009). The Use of Multispectral Images for the Classification of Agricultural Crops // Ecology and Noosphere, - № 1-2, - pp. 54-58. 